\title{
Muscadine Grape Response to Drip Irrigation Rate
}

\author{
D. Scott NeSmith \\ Department of Horticulture, University of Georgia, 1109 Experiment Street, \\ Griffin, GA 30223-1797
}

Additional index words. water deficit, soil water content, yield, daily irrigation

\begin{abstract}
During 1997 through 1999 mature 'Southland' muscadine grapes were grown

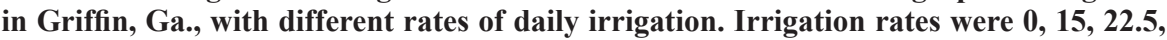
and $30 \mathrm{~L} \cdot \mathrm{d}^{-1}$, supplied to individual plants through two emitters. Substantial water deficit occurred during August 1997, May and June 1998, and July and August 1999. The greatest yield response to irrigation was observed during 1998. No significant response to irrigation was observed during 1999 , even though soil water was greatly depleted in the upper $30 \mathrm{~cm}$ late in the season for control plants. The 3-year average response of total yield indicated a significant response to irrigation, with the greatest yield occurring at the $22.5-\mathrm{L} \cdot \mathrm{d}^{-1}$ rate. Together these data suggest that muscadine grapes respond to irrigation, especially when water deficits during the early to midseason are prevalent. With single trellis vines, $22.5 \mathrm{~L} \cdot \mathrm{d}^{-1}$ should provide adequate water in warm, humid regions similar to the southeastern U.S.
\end{abstract}

Muscadine grape (Vitis rotundifolia Michx.) is an important small fruit crop in the southeastern U.S., both for commercial operations and for home gardeners. The species of grape is well adapted to the heat of the southeast, and is quite common in the wild. However, little is known about the water requirements of this crop in relation to yields. Research has shown positive responses of vinifera grapes (Vitis vinifera L.) to drip irrigation (Bucks et al., 1985; Grimes and Williams, 1990; Hamman and Dami, 2000), yet, a study with muscadine grapes indicated little benefit from irrigation (Austin and Bondari, 1988).

The southeastern U.S. has experienced near record droughts in the past few years, and this has caused increased concern for efficient utilization of irrigation resources. Therefore, muscadine growers need to have additional information on how irrigation should be used in the production of their crop. The objective of this research was to determine the response of established muscadine grape vines to different rates of daily irrigation.

\section{Materials and Methods}

This research was conducted during 1997 through 1999 in an established 'Southland' muscadine vineyard located on a University of Georgia Experiment Station Research Farm near Griffin, Ga. The soil at the site was a Cecil sandy clay loam (Typic Hapludult). The vineyard was 5 years old at the onset of this irrigation experiment, and plants were previously irrigated only a limited amount to assist in establishment. Plant arrangement in the vineyard was a $3.0-\mathrm{m}$ spacing in the row and a $3.7-\mathrm{m}$ spacing between rows. Plants

Received for publication 22 Sept. 2004. Accepted for publication 1 Nov. 2004. A contribution of the University of Georgia Agricultural Experiment Stations, Georgia Station, Griffin. This research was supported by state and Hatch Act funds allocated to the Georgia Agricultural Experiment Stations.
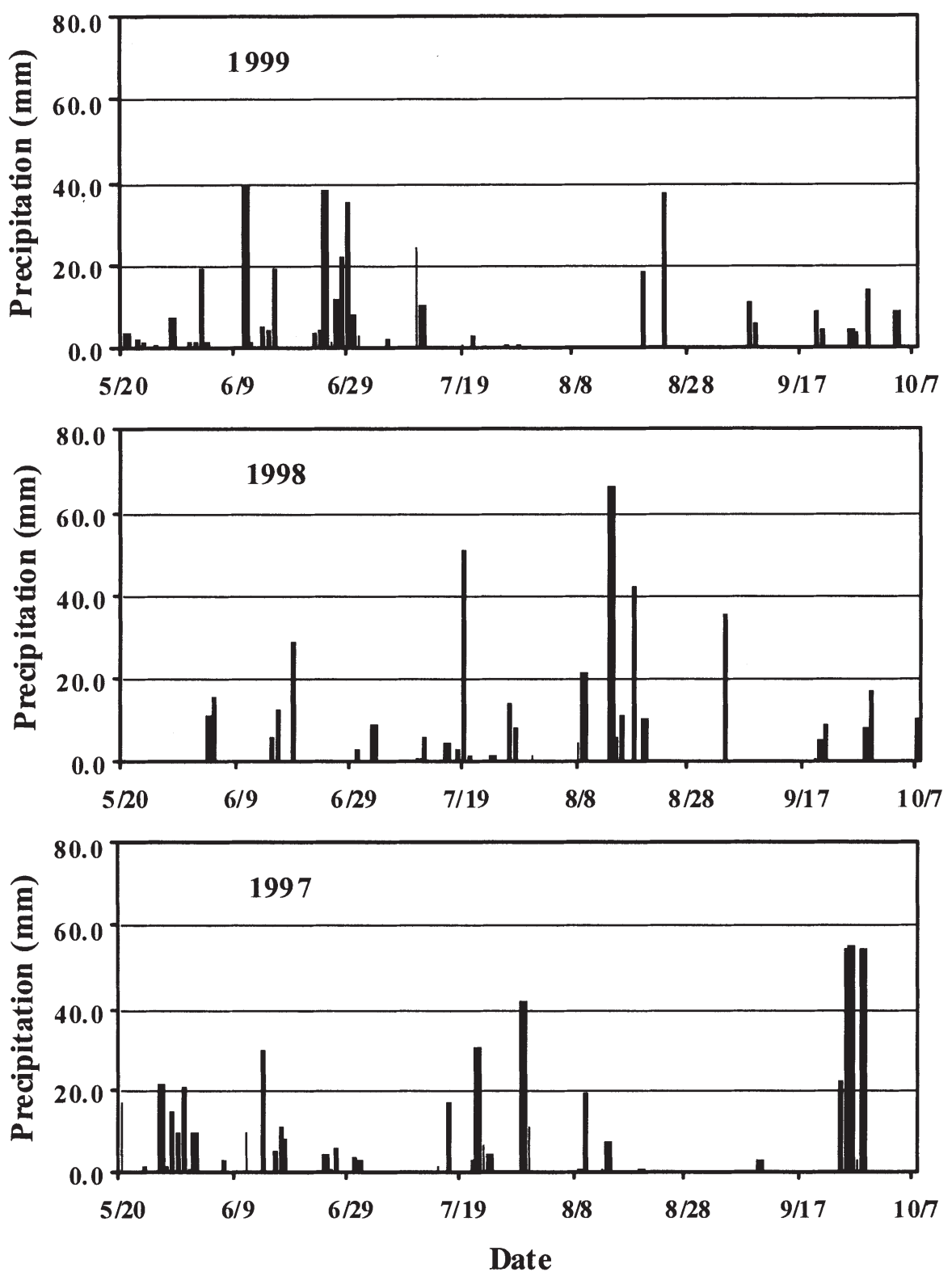

Fig. 1. Rainfall distribution during 1997, 1998, and 1999 at Griffin, Ga. 
had been trained to a single-wire trellis, and annual pruning was conducted. Weed control, fertilization, and disease control measures were those typical of a commercial vineyard (Krewer et al., 1999).

In late spring 1997, drip irrigation plots were installed on the plants. There were four irrigation regimes: no irrigation, or rates of $15,22.5$, or $30 \mathrm{~L} \cdot \mathrm{d}^{-1}$ per plant. The irrigation rates were achieved using emitters with different flow volumes $\left(3.8,5.7\right.$, or $\left.7.6 \mathrm{~L} \cdot \mathrm{h}^{-1}\right)$. Two emitters of the desired flow volume were placed $30 \mathrm{~cm}$ from the base of the main trunk in opposite directions in the plant row. All irrigation was applied for $2 \mathrm{~h}$ daily, beginning in late May and running through the middle of October each year. Emitter output was checked each season by using catchments and measuring the volume of water over a specified time interval. Each irrigation plot contained three plants and was replicated four times. The experimental arrangement was a randomized complete block design.

Soil water content was measured for the center plant in each plot using the time-domain reflectometry (TDR) technique (Anisko et al., 1994), and a calibration curve previously derived for the soil in a separate experiment (Panta, 1995). TDR rods were placed in the soil to a depth of $30 \mathrm{~cm}$, about half-way between emitters in the row, $10 \mathrm{~cm}$ from the base of the plant. Periodic TDR readings were taken during each growing season. Attempts were made to determine soil water data just after prolonged periods of drying, or after major rain events. Precipitation and pan evaporation data were obtained from a weather station of the GeorgiaAutomated Environmental Monitoring Network (http://www.griffin.uga.edu/bae/), located $<1000 \mathrm{~m}$ from the vineyard.

Yields were derived each year from one (1999) or two (1997 and 1998) harvests. Fruit were hand-harvested from the center plant of each plot, and total weights were obtained. A subsample of fruit (two 25-berry samples per plant) was used to determine individual berry weight and soluble solids at each harvest. All plant data were subjected to analysis of variance procedures.

\section{Results}

Precipitation pattern varied considerably for each year (Fig. 1). In 1997 and 1998, precipitation was low during late June to mid-July. Rainfall was plentiful during this same time period in 1999. There was an extended period of low rainfall from mid-July to mid-August during 1999, however. Using data from a nearby weather station, a monthly water balance (total precipitation-total pan evaporation) was calculated for each year (Table 1). These data indicate a moderate to heavy water deficit occurred in June 1997 and 1998, while during June 1999 there was a substantial precipitation surplus. Large water deficits occurred during August 1997 and 1999, while a moderate to heavy water deficit occurred during July of each year. The 30 -year average water balance from May through October indicates a water deficit is typical during each month.

Table 1. Monthly water balance (total precipitation - total pan evaporation) for May through October during 1997, 1998, and 1999 in Griffin, Ga. A positive number indicates precipitation exceeded evaporative demand, and a negative number indicates evaporative demand exceeded precipitation.

\begin{tabular}{lrrrc}
\hline & \multicolumn{3}{c}{ Water balance (precipitation - evaporation) (mm) } \\
\cline { 2 - 4 } Month & 1997 & 1998 & 1999 & $30-$ Year avg \\
\hline May & -11.2 & -85.3 & -53.3 & -41.7 \\
June & -21.8 & -87.6 & 100.1 & -61.0 \\
July & -30.0 & -48.8 & -98.8 & -39.6 \\
August & -106.4 & 21.1 & -93.5 & -36.6 \\
September & 88.1 & -26.4 & -48.8 & -33.3 \\
October & 41.4 & -82.3 & 27.4 & -16.3 \\
\hline
\end{tabular}

Table 2. Total fruit yield for 'Southland' muscadine grapes in response to different daily drip irrigation rates in Griffin, Ga., during 1997, 1998, and 1999.

\begin{tabular}{|c|c|c|c|c|}
\hline \multirow{2}{*}{$\begin{array}{l}\text { Daily irrigation } \\
\text { amount/plant } \\
\text { (L) }\end{array}$} & \multicolumn{4}{|c|}{ Total yield (kg/plant) } \\
\hline & 1997 & 1998 & 1999 & 30-Year avg \\
\hline 0 & 16.9 & 14.8 & 13.3 & 15.0 \\
\hline 15 & 18.7 & 19.4 & 16.0 & 18.0 \\
\hline 22.5 & 21.6 & 22.6 & 18.0 & 20.7 \\
\hline 30 & 21.6 & 21.4 & 16.1 & 19.7 \\
\hline \multicolumn{5}{|l|}{ Significance } \\
\hline $\mathrm{L}$ & NS & $* *$ & NS & $* *$ \\
\hline Q & $*$ & $* *$ & NS & $* *$ \\
\hline
\end{tabular}

Yields in response to irrigation regimes are depicted in Table 2. The data indicate a significant quadratic response of yield to irrigation rate for both 1997 and 1998, while there was no significant irrigation effect observed during 1999. During 1997 and 1998, peak yields were observed for the $22.5-\mathrm{L} \cdot \mathrm{d}^{-1}$ irrigation treatment. No additional yield increases were observed for the $30-\mathrm{L} \cdot \mathrm{d}^{-1}$ treatment. The 3 -year average yield response indicated all irrigation treatments were greater than the control, but again, yields peaked at an irrigation rate of $22.5 \mathrm{~L} \cdot \mathrm{d}^{-1}$. Over the 3 -year period, the $15-\mathrm{L} \cdot \mathrm{d}^{-1}$ irrigation treatment yielded $20 \%$ more than the control, and the $22.5-\mathrm{L} \cdot \mathrm{d}^{-1}$ treatment yielded $38 \%$ more. Yields for treatments were similar for 1997 and 1998; however, there was an overall tendency for lower yields during 1999 for all treatments. There were no significant effects of irrigation in any year on berry size or soluble solids (data not shown).

Soil water content data are portrayed in Fig. 2. Measurements did not begin until late in the season during the first year, but season long measurements were made during subsequent years. The patterns for soil water content corresponded to those expected from the rainfall patterns received each year. The 22.5- and $30-\mathrm{L} \cdot \mathrm{d}^{-1}$ irrigation regimes generally kept soil water capacity high throughout the growing season each year, with little differences between those treatments. During drying periods, the 0 - and $15-\mathrm{L} \cdot \mathrm{d}^{-1}$ irrigation treatments showed a significant decline in soil water content, although the $15-\mathrm{L} \cdot \mathrm{d}^{-1}$ soil water content was generally higher than the control.

\section{Discussion}

In a previous multiyear, multifactor study with muscadines in Georgia, little response to irrigation was denoted overall, although, the authors did observe increases in some years due to irrigation (Austin and Bondari, 1988; Austin et al., 1988). The vines used in that study were $>30$ years old at the onset of the irrigation experiment. In the current study, much younger vines were used, and the data declared an overall benefit of irrigation, although as with many crops a positive response cannot be expected every year due to varying rainfall patterns. Perhaps installing irrigation on very old muscadines may be of less benefit than if irrigation is used shortly after establishment.

Yields from 1997 and 1998 showed the greatest response to irrigation in the current study. Moderate to high water balance deficits were present during June and July in each of those years. This corresponds to the flowering and early fruit growth stages for muscadines in this geographic area. Likely, this is a sensitive stage for obtaining favorable yields, and water deficits during that time can reduce crop loads. During 1999, a year when little differences were observed between irrigation treatments, June and early July were characterized by positive water balances, although, severe water deficits occurred during late July and August. The later season deficits in 1999 could account for the depressed yields for all treatments during that year, however, soil water content data suggest otherwise since the 22.5 - and $30-\mathrm{L} \cdot \mathrm{d}^{-1}$ irrigation regimes had favorable soil water content.

In a recent 1-year study in Colorado with $V$. vinifera (Hamman and Dami, 2000), it was reported that an irrigation rate of $96 \mathrm{~L} \cdot \mathrm{week}^{-1}$ $\left(13.7 \mathrm{~L} \cdot \mathrm{d}^{-1}\right)$ yielded the same as a $192 \mathrm{~L} \cdot$ week $^{-1}$ $\left(27.4 \mathrm{~L} \cdot \mathrm{d}^{-1}\right)$ irrigation regime and $44 \%$ more

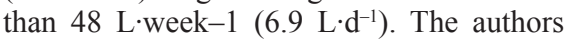
concluded that a moderate irrigation treatment $\left(13.7 \mathrm{~L} \cdot \mathrm{d}^{-1}\right)$ could conserve water without reducing yields. In the current 3-year study with muscadine grapes, an irrigation rate of $15 \mathrm{~L} \cdot \mathrm{d}^{-1}$ yielded more than no irrigation, but it yielded $<22.5 \mathrm{~L} \cdot \mathrm{d}^{-1}$ on average. Optimum irrigation regimes for muscadines in the warm, humid southeast likely are different than those reported elsewhere for $V$. vinifera. However, if water supply is limited, or if water conservation is imperative, the muscadine data indicate 

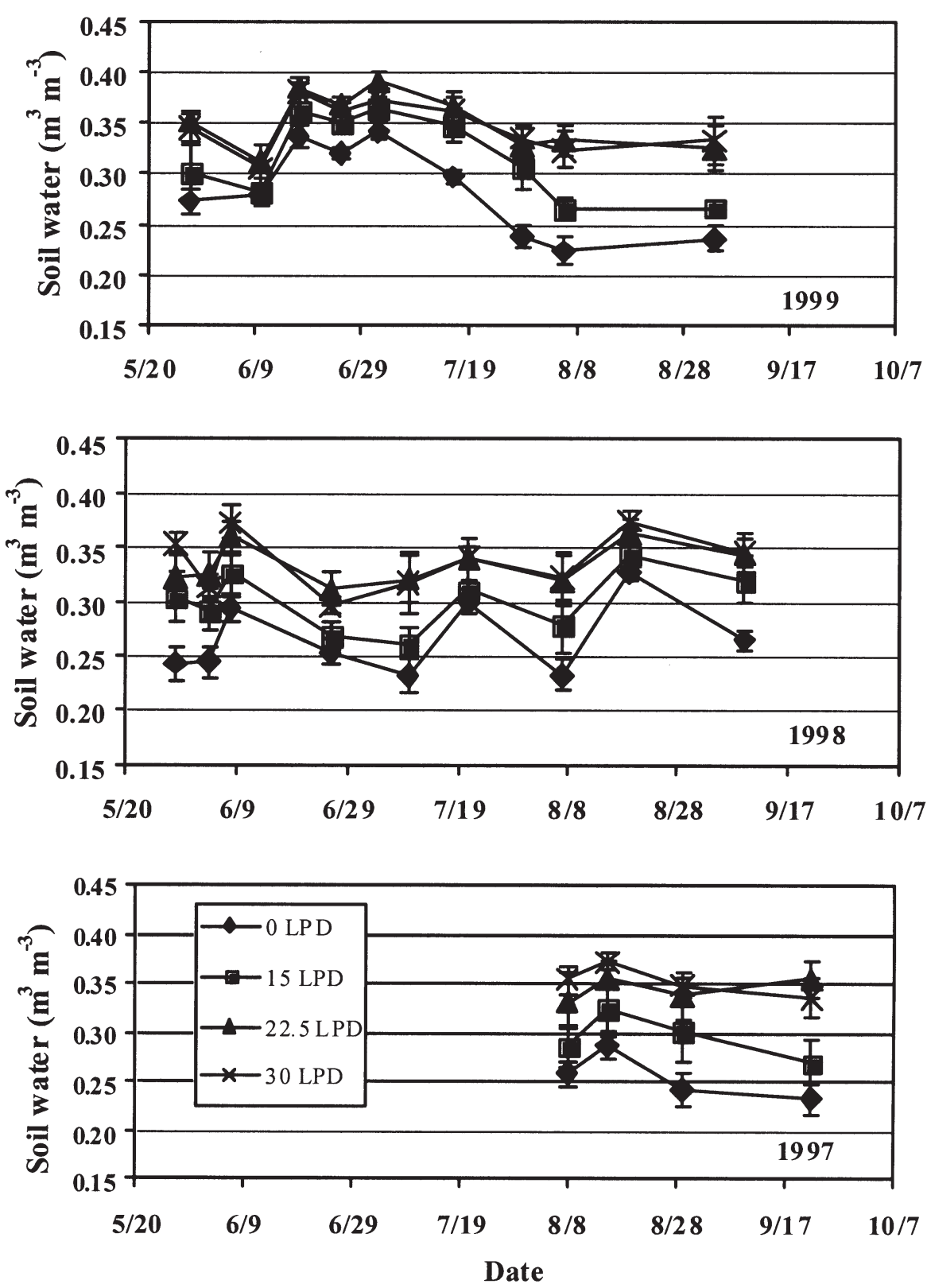

Fig. 2. Volumetric soil water content for different muscadine irrigation treatments as determined using time domain reflectometry (TDR) during 1997, 1998, and 1999 in Griffin, Ga.

a positive benefit can still be gained from less water, but not optimum yields.

Hamman and Dami (2000) also observed greater average berry weight and increased soluble solids in response to increased irrigation rate. The current study with muscadines revealed no differences in berry size or soluble solids in response to irrigation. Again, this could be a species difference, or just a cultivar conserving water. In fact, daily irrigations coupled with water deficit monitoring is one of the best ways to conserve water in a humid region. If large applications of water are made only 1 to 3 times a week, and heavy rainfall occurs shortly after the irrigation event, then some of the water will not be beneficial. Unfortunately, growers often fail to monitor irrigation systems unless there are several consecutive days of rain. Growers are urged to consider using automated devices for operating irrigation based on rainfall occurrence, which would increase efficiency.

In summary, muscadine grapes in the Southeast likely will respond to irrigation, especially when periods of water deficit are experienced early to midseason. While irrigation needs can vary depending on soil, climate, trellis type, etc., it appears that a daily rate of $22.5 \mathrm{~L} \cdot \mathrm{d}^{-1}$ is near optimum for muscadines. Application amounts greater than this were not beneficial, while less irrigation amount resulted in lower yield. Monitoring soil water content can be useful in irrigation scheduling, but this is usually cumbersome for most growers. However, daily reports of pan evaporation and precipitation can easily be obtained and would be useful in guiding irrigation.

\section{Literature Cited}

Anisko, T., D.S. NeSmith, and O.M. Lindstrom. 1994. Time-domain reflectometry for measuring water content of organic growing media in containers. HortScience 29:1511-1513.

Austin, M. and K. Bondari. 1988. A study of cultural and environmental factors on the yield of Vitis rotundifolia. Scientia Hort. 34:219-227.

Austin, M., K. Bondari, and W.T. Brightwell. 1988. Effects of plant spacing, trellis system, irrigation, fertilizer rate, and spur thinning on the yield of muscadine grape. Univ. Ga. CollegeAgr. Environ. Sci. Ga. Agr. Expt. Sta. Res. Bul. T-368.

Bucks, D.A., O.F. French, F.S. Nakayama, and D.D. Fangmeier. 1985. Trickle irrigation management for grape production, p. 204-211. Proc. 3rd Intl. Drip/Trickle Irr. Congr., Fresno, Calif.Amer. Soc. Agr. Eng.Publ. 10-85.

Grimes, D.W. and L.E. Williams. 1990. Irrigation effects on plant water relations and productivity of Thompson seedless grapevines. Crop Sci. 30:255-260.

Hamman, Jr., R.A. and I.E. Dami. 2000. Effects of irrigation on wine grape growth and fruit quality. HortTechnol. 10:162-168.

Krewer, G., M. Hall, D.S. NeSmith, D. Horton, H. Scherm, P. Sumner, T. Tyson, and G. Westberry. 1999. Commercial muscadine culture. Univ. Georgia College Agr. Environ. Sci. Bul. 739.

Panta, G.R. 1995. Physiological and morphological responses of squash to water deficit stress. MS thesis. Univ. Ga., Athens. 